\title{
Magneto-sensitive rubber in the audible frequency range
}

\author{
Peter Blom
}

Stockholm 2006

Doctoral Thesis

Royal Institute of Technology

School of Engineering Sciences

Department of Aeronautical and Vehicle Engineering

The Marcus Wallenberg Laboratory for Sound and Vibration Research 
Akademisk avhandling som med tillstånd av Kungliga Tekniska Högskolan i Stockholm framlägges till offentlig granskning för avläggande av teknologie doktorsexamen den 14 juni 2006, kl 13.00 i F3, Lindstedtsvägen 26, KTH, Stockholm.

ISBN -91-7178-392-X

TRITA-AVE -2006:37

ISSN -1651-7660

(c) Peter Blom, June 2006 



\section{Preface}

This work was started in October 2003 as a continuation of my diploma work on magneto-sensitive rubber. It was financed by the Swedish Research Council (Contract no: 621-2002-5643); I gratefully acknowledge this support.

I owe my gratitude to many people for the success of this thesis. Most of all, to my supervisor Leif Kari for his brilliant guidance-based among other things on a strong and exuberant enthusiasm, a genuine physical insight and an invariably happy mood. From day one, I experienced a stimulating and comfortable work atmosphere, the importance of which cannot be stressed enough. My fellow Ph.D. students - those that I have shared office and had lunch with practically every day for the last few years, and those together with whom I have struggled through courses or simply drunk staggering amounts of coffees with - have alongside the rest of my colleagues been essential elements in the building of a pleasant and inviting work place.

To my friends, especially my closer ones, that over the past years have offered me invaluable, never waning support, I would like to express my warmest thanks. I'll buy you one!

Finally, it is almost too easy to forget something that has always been taken for granted, such as the cordial support that I have always been extremely fortunate to receive from my family. Its importance to me expressed in words, would easily outsize this thesis. Thank you! 



\begin{abstract}
The dynamic behaviour in the audible frequency range of magneto-sensitive (MS) rubber is the focus of this thesis consisting of five papers $(\mathbf{A}-\mathbf{E})$. Paper $\mathbf{A}$ presents results drawn from experiments on samples subjected to different constant shear strains over varying frequencies and magnetic fields. Main features observed are the existence of an amplitude dependence of the shear modulus - referred to as the Fletcher-Gent effect - for even small displacements, and the appearance of large MS effects. These results are subsequently used in Paper B and C to model two magneto-sensitive rubber isolators, serving to demonstrate how, effectively, by means of MS rubber, these can be readily improved. The first model calculates the transfer stiffness of a torsionally excited isolator, and the second one, the energy flow into the foundation for a bushing inserted between a vibrating mass and an infinite plate. In both examples, notable improvements in isolation are obtainable. Paper D presents a non-linear constitutive model of MS rubber in the audible frequency range. Characteristics inherent to magneto-sensitive rubber within this dynamic regime are defined: magnetic sensitivity, amplitude dependence, elasticity and viscoelasticity. A very good agreement with experimental values is obtained. In Paper $\mathbf{E}$, the magneto-sensitive rubber bushing stiffness for varying degrees of magnetization is predicted by incorporating the non-linear magneto-sensitive audio frequency rubber model developed in Paper $\mathbf{D}$, into an effective engineering formula for the torsional stiffness of a rubber bushing. The results predict, and clearly display, the possibility of controlling over a large range through the application of a magnetic field, the magneto-sensitive rubber bushing stiffness.
\end{abstract}

Key words: Magneto-sensitivity, Rubber, Audible frequency range, Amplitude dependence, Vibration isolator, Fletcher - Gent effect, Stiffness 



\section{Dissertation}

The doctoral thesis consists of this summary and five appended papers listed below and referred to as Paper A to Paper E.

\section{Paper A}

P. Blom, L. Kari 2005: "Amplitude and frequency dependence of magneto-sensitive rubber in a wide frequency range." Printed by Polymer Testing.

\section{Paper B}

L. KARI, P. BLOM 2005: "Magneto-sensitive rubber in a noise reduction context - exploring the potential." Printed by Plastics, Rubber and Composites: Macromolecular Engineering.

\section{Paper C}

P. BLOM, L. KARI 2005: "Smart audio frequency energy flow control by magneto-sensitive rubber isolators." Submitted to Smart Materials and Structures.

\section{Paper D}

P. Blom, L. KARI 2006: "A non-linear constitutive audio frequency magneto-sensitive rubber model including amplitude, frequency and magnetic field dependence." Submitted to Smart Materials and Structures.

\section{Paper E}

P. BLOM, L. KARI 2006: "The frequency, amplitude and magnetic field dependent torsional stiffness of a magneto-sensitive rubber bushing." Submitted to International Journal of Mechanical Sciences. 



\section{Contents}

1 Introduction 1

2 Properties of MS rubber in the audible frequency range $\quad 2$

2.1 Magneto-sensitivity . . . . . . . . . . . . . . . 6

2.2 Dynamic amplitude dependence - The FletcherGent effect . . . . . . . . . . . . . . 6

2.3 Frequency dependence . . . . . . . . . . . . . . 7

2.4 Elastic dependence . . . . . . . . . . . . . 8

3 Modelling of MS rubber in the audible frequency range 8

3.1 Elasticity . . . . . . . . . . . . . . . 10

3.2 Viscoelasticity . . . . . . . . . . . . . . . 10

3.3 Frictional stress response . . . . . . . . . . . . 10

3.4 Magneto-sensitivity . . . . . . . . . . . . . 11

3.5 Total behaviour . . . . . . . . . . . . . 11

4 Applications-MS rubber isolators $\quad 12$

4.1 Torsionally excited cylindrical isolator . . . . . 14

4.2 Axially excited MS rubber bushing . . . . . . 16

4.3 Torsionally excited MS rubber bushing . . . . 19

5 Future Research $\quad 27$

$\begin{array}{ll}\text { References } & 28\end{array}$ 



\section{Introduction}

The term smart materials - roughly defined as materials whose properties can be changed to meet changing conditions - was coined some twenty years ago and has since attracted enormous interest from researchers and industrials alike. To people in general, however, it was not until recently that these materials clearly prove their utility, albeit only on film; in the latest Batman movie, "Batman Begins"(2005), the hero drapes himself in a velvet-like, soft cape, as he swirls around Gotham City instilling fear in criminals, dressed up in his horrifying disguise. Visual effects aside, this garment of his also possesses some other, extraordinary, qualities; in contrast to conventional super hero capes this one differs, insofar as passing an electric current across it, renders it hard as steel, protecting Batman from bullets' harm. While seemingly fantasy-like, the mind leap to the subject treated in this thesis is actually not gigantic.

Narrowing down the wide concept of smart materials to that of magnetosensitive materials the research into this field was started in the end of the forties by Rabinow (1) who was working on magneto-sensitive fluids. Concurrently, Winslow (2) was working on electro-sensitive (ES) fluids. In tandem with their discoveries, research on MS and ES materials gained momentum, but focus remained all the same until recently on ES materials. This while MS materials have proven more commercially successful, lately prompting a large number of publications of research reports on MS fluids and solids alike refs.(3)-(13). Magneto-sensitive rubber has become the subject of much research because of the wide presence of rubber in applications such as bushings and engine mounts for instance; the interest lies in the capability to dynamically change the apparent rubber stiffness and damping, achieved by applying a magnetic field over a rubber containing iron particles.

In Paper $\mathbf{A}$ included in this thesis the shear modulus and its magnetic sensitivity in the audible frequency range have been studied from 100 to $1000 \mathrm{~Hz}$ at different, constant strains. Due to the wide frequency span, visco-elastic effects are covered in addition to magnetic ones, while 
simultaneously at all strains allowing for observation of the FletcherGent effect - the rubber is subjected to constant shear strains as small as $0.0084 \%$. The influence of this effect is normally negligible for unfilled rubber subject only to small strains. However, it will be shown that this assumption is not valid for MS rubber. In this manner a more complete understanding of the separate effects of magneto-sensitive materials in the audible frequency range and their relative importance are obtained. Furthermore, the magneto-sensitivity is revealed to be surprisingly large, especially for small amplitudes. In Paper $\mathbf{B}$ and $\mathbf{C}$, which are theoretical applications based on the experimental results obtained in Paper A, it is revealed how vibration isolators in two cases can be greatly improved by adopting magneto-sensitive rubber. Paper D presents a model of magneto-sensitive rubber in the audible frequency range. In contrast to the large majority of existing magneto-sensitive elastomer models, this one involves viscoelasticity. It moreover accounts for the non-linear amplitude dependence usually neglected in static, quasi-static and dynamic models for small strains. In Paper E, the model presented in Paper $\mathbf{D}$ is incorporated into an engineering formula for the torsional stiffness of a long rubber bushing. The results from the calculations predict and clearly display the possibility of controlling over a large frequency range, through the application of a magnetic field, the magneto-sensitive rubber bushing stiffness.

\section{Properties of MS rubber in the audible frequency range}

Rubber is a material of complex nature. In order to aptly describe its behaviour three principal features need be accurately captured: elasticity, viscoelasticity and amplitude dependence. Moreover, as for MS rubber, the introduction of magnetizable particles in the rubber along with a possibly applied magnetic field complicates the task further. Since in this thesis only small strains are considered - such strains are commonly 
encountered in the audible frequency range - geometrical non-linearities are henceforth disregarded. To comprehend the importance of the various effects observed, thorough experimental studies are required. Such performed studies are presented in Paper A. A test rig [Fig. 1] was designed for dynamic shear modulus measurements. In this rig two rubber samples are simultaneously sheared at frequencies between 100 and 1000 $\mathrm{Hz}$ with different constant amplitude, while exposed to a magnetic field of varying strength. Two kinds of rubber, natural and silicone rubber, each containing $33 \%$ iron are tested. The iron particles are randomly dispersed and of irregular shape, with a particle size distribution of $77.7 \%$ :

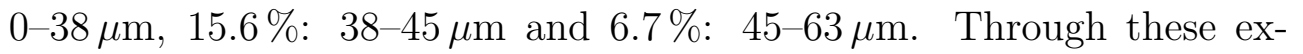
periments, magneto-sensitivity, dynamic amplitude dependence and frequency dependence can be observed. Furthermore, through analysis and modelling, the influence of magnetic exposure on the respective effects can be comprehended. 


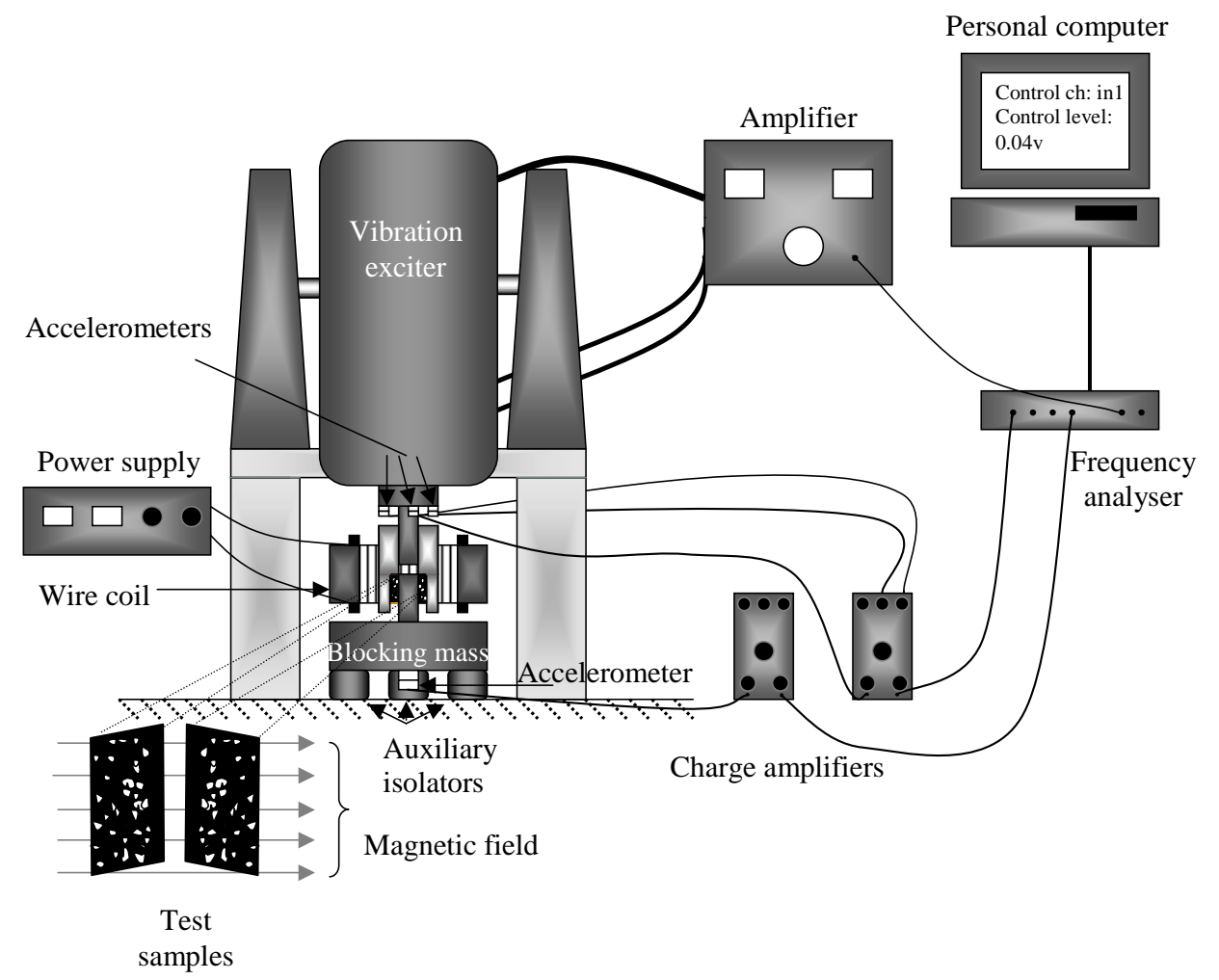

Figure 1: Measurement set-up 


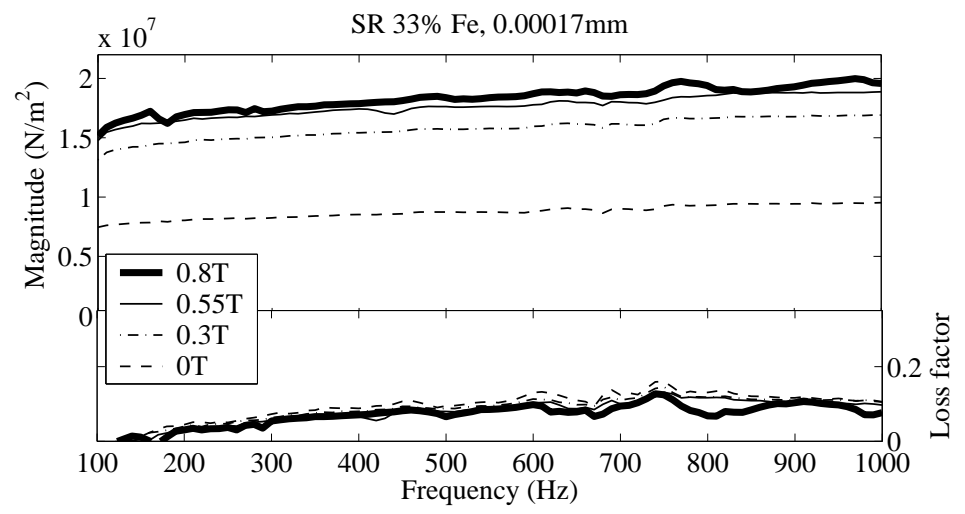

Figure 2: Shear modulus magnitude $|G|$ and loss factor Imag $G /$ Real $G$ versus frequency at induced magnetic field of $0,0.3,0.55$ and $0.8 \mathrm{~T}$, and constant displacement amplitude of $0.00017 \mathrm{~mm}$.

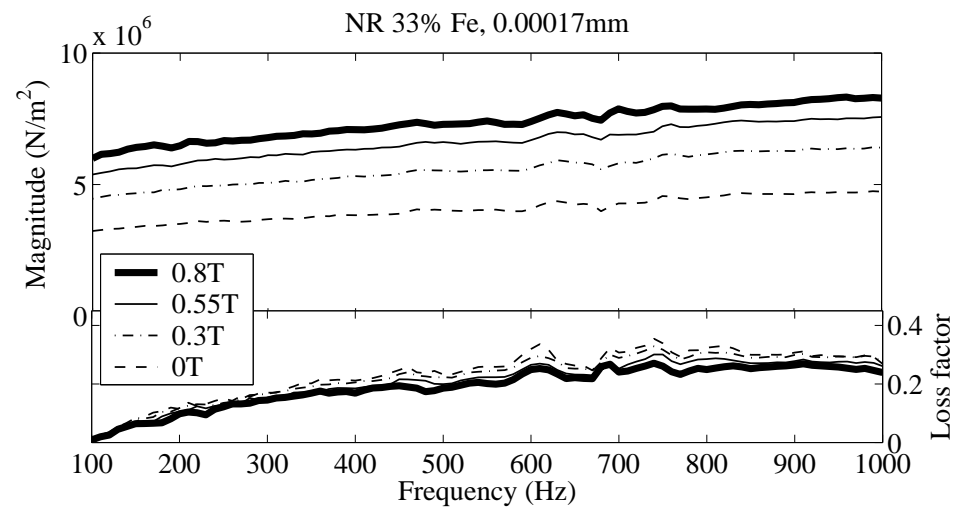

Figure 3: Shear modulus magnitude $|G|$ and loss factor Imag $G /$ Real $G$ versus frequency at induced magnetic field of $0,0.3,0.55$ and $0.8 \mathrm{~T}$, and constant displacement amplitude of $0.00017 \mathrm{~mm}$. 


\subsection{Magneto-sensitivity}

The application of a magnetic field gives rise to a magnetic dipole-dipole interaction between the iron particles causing the apparent changes in stiffness and damping. This phenomenon occurs instantly and reversibly. The results for the smallest amplitude for the silicone and natural rubber are displayed in Figs. 2 and 3. Their respective behaviours are practically similar displaying only minor differences; the strong magneto-sensitivity can be viewed in both figures for the magnitude of the shear modulus. For the first case a $115 \%$ increase is observed, while for the second case it is a little less, yet very strong. Furthermore, it will subsequently be shown that the increase in shear modulus magnitude with magnetic field grows with decreasing amplitude at all frequencies, a phenomenon linked to the dynamic amplitude dependence.

\subsection{Dynamic amplitude dependence- The Fletcher- Gent effect}

The dynamic shear modulus displays an amplitude dependence that is relatively large for even the smallest amplitudes. This can be deduced by comparing the curves in Figs. 4 and 5 representing shear modulus versus strain at four different magnetic fields. Analysis of those graphs leads to the following: a decreasing vibration amplitude gives rise to an increasing magnitude and decreasing loss factor of the shear modulus. This behaviour derives from a phenomenon referred to as the Fletcher-Gent effect (14), whose influence on rubber subjected to small deformations is normally negligible. However, these observations reveal that in a wide amplitude range the Fletcher-Gent effect is a highly important feature of MS rubber. The effect grows stronger with higher magnetic inductions implying that there be a relation between the amplitude dependence and the magneto-sensitivity. The Fletcher-Gent effect is usually modelled as a frictive effect. Thus it can roughly be said that the stronger the amplitude dependence, the higher the losses, suggesting that for higher magnetic fields the Fletcher-Gent effect should give a positive contribu- 
tion to the total loss factor.
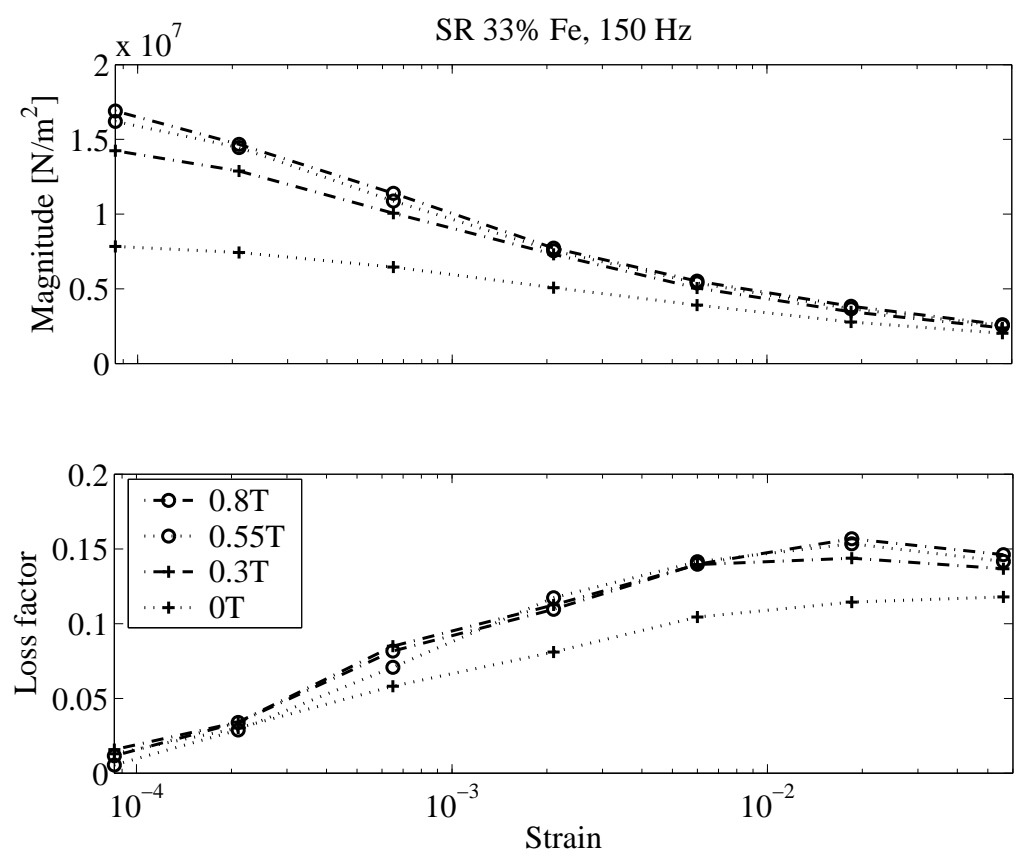

Figure 4: Shear modulus magnitude $|G|$ and loss factor Imag $G /$ Real $G$ versus strain at $150 \mathrm{~Hz}$ and induced magnetic fields of $0,0.3,0.55$ and $0.8 \mathrm{~T}$.

\section{$2.3 \quad$ Frequency dependence}

The shear modulus magnitude and loss factor grow with frequency in an expected rubber like fashion for all magnetic fields and amplitudes for both the silicone and natural rubber. This implies that, not surprisingly, the viscoelastic properties of rubber are retained for MS rubber. Moreover, the shear modulus magnitude difference between the zero-field and saturated state at different frequencies appears to be relatively constant suggesting that the viscoelastic dependence on magnetic induction be small. 

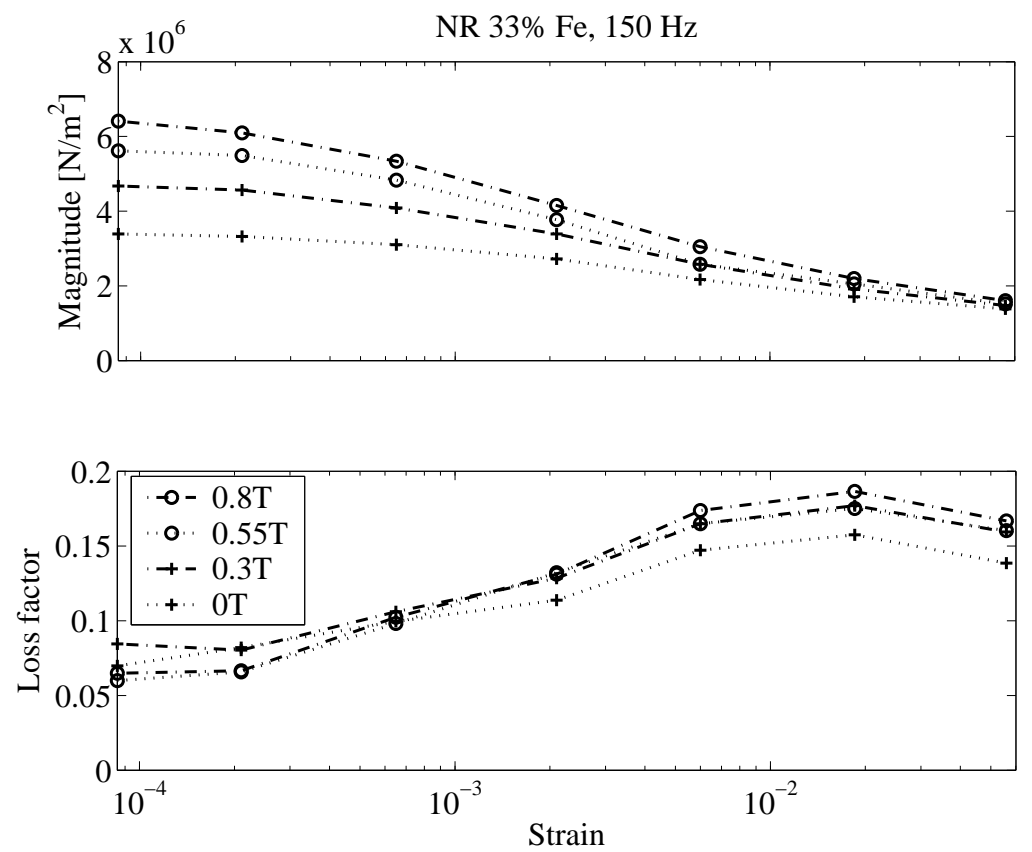

Figure 5: Shear modulus magnitude $|G|$ and loss factor Imag $G /$ Real $G$ versus strain at $150 \mathrm{~Hz}$ and induced magnetic fields of $0,0.3,0.55$ and $0.8 \mathrm{~T}$.

\section{$2.4 \quad$ Elastic dependence}

As is also the case of conventionally used rubber, MS rubber is partly elastic. Observing that the total loss factor varies little with magnetic field, suggests that the loss increase with increasing magnetic field that the Fletcher-Gent effect gives rise to, be balanced by an increase in the elastic modulus.

\section{Modelling of MS rubber in the audible frequency range}

While some existing rubber models include amplitude dependence refs.(15)(19), none of them includes magneto-sensitivity. Conversely, even though 
recent years have witnessed a steep rise in the number of research reports on magneto-sensitive fluids and solids alike, the majority focus merely on the quasi-static properties refs.(20)-(25) often excluding the amplitude dependence, as well as the frequency dependence. Nevertheless, in recent publications refs.(26)-(29) the amplitude dependence is revealed to be an important feature for magneto-sensitive rubber even at small strains. Moreover, the magnetic sensitivity is shown to be strongly amplitude dependent, why the inclusion of such effects in a model is essential to accurately reflect the physical phenomena present.

Based on the presented properties a constitutive model of MS rubber in the audible frequency range is presented in Paper D.

The total stress response is assumed to be additively decomposable into three parts depending on time $t$,

$$
\tau=\tau_{\mathrm{e}}+\tau_{\mathrm{ve}}+\tau_{\mathrm{f}}
$$

where the elastic stress $\tau_{\mathrm{e}}(t)$ is linearly related to the instantaneous strain $\gamma(t)$, the viscoelastic stress $\tau_{\text {ve }}(t)$ is linearly related to the history of the strain rate and the friction stress $\tau_{\mathrm{f}}(t)$ is non-linearly related to the strain.

Since time domain expressions quickly become cumbersome, relationships are often studied in the frequency domain where they are largely reduced in size; also in this manner calculations are readily simplified, especially if linearity can be assumed. This domain change can be performed without any loss of information for the elastic and viscoelastic components of linear nature. On the other hand, the non-linear frictional component will react to a single frequency sinusoidal strain by yielding one stress component of the same frequency as the input, and an infinite number of overtones of odd multiple order of that input frequency. These overtones, however, decay rapidly in amplitude and can therefore be dropped in analyses when studying linearized relationships between input and output; the linearized shear modulus being an example of this. Once that linearization has been performed, the following frequency domain relation can be established 


$$
G=\frac{\widetilde{\tau}(\omega)}{\widetilde{\gamma}(\omega)}
$$

where the $\widetilde{r}$ symbol is henceforth employed for frequency domain quantities obtained by applying the temporal Fourier transform

$(\widetilde{\cdot})=\int_{-\infty}^{\infty}(\cdot) \exp (-\mathrm{i} \omega t) \mathrm{d} t ; \omega$ is the angular frequency in radians per second and $G$ the linearized shear modulus in the frequency domain.

\subsection{Elasticity}

The elastic dependence is simply described by

$$
\tau_{\mathrm{e}}=G_{\mathrm{e}} \gamma
$$

where $G_{\mathrm{e}}$ is the elastic shear modulus.

\subsection{Viscoelasticity}

The viscoelastic stress $\tau_{\mathrm{ve}}(t)$ is linearly related to the history of the strain rate ref.(30),

$$
\tau_{\text {ve }}=\frac{b}{\Gamma(1-\alpha)} \frac{\mathrm{d}}{\mathrm{d} t} \int_{-\infty}^{t} \frac{\gamma(s)}{(t-s)^{\alpha}} \mathrm{d} s \quad 0<\alpha \leq 1, \quad b>0,
$$

where $\Gamma$ is the gamma function and $\alpha$ and $b$ are material constants.

\subsection{Frictional stress response}

The friction stress $\tau_{\mathrm{f}}(t)$ is nonlinearly related to the strain refs. $(18 ; 31)$ as

$$
\tau_{\mathrm{f}}=\tau_{\mathrm{fs}}+\frac{\gamma-\gamma_{\mathrm{s}}}{\gamma_{1 / 2}\left[1-\operatorname{sign}(\dot{\gamma}) \frac{\tau_{\mathrm{fs}}}{\tau_{\mathrm{fmax}}}\right]+\operatorname{sign}(\dot{\gamma})\left[\gamma-\gamma_{\mathrm{s}}\right]}\left[\tau_{\mathrm{fmax}}-\operatorname{sign}(\dot{\gamma}) \tau_{\mathrm{fs}}\right],
$$

where the maximum friction stress developed $\tau_{\text {fmax }}$ and $\gamma_{1 / 2}$ are model constants with $\operatorname{sign}(\dot{\gamma})$ yielding the direction of the displacement. The parameters $\tau_{\mathrm{fs}}$ and $\gamma_{\mathrm{s}}$ are updated each time there is a change in shear direction at $\dot{\gamma}_{\mathrm{s}}=0$ as $\left.\tau_{\mathrm{fs}} \leftarrow \tau_{\mathrm{f}}\right|_{\dot{\gamma}=0}$ and $\left.\gamma_{\mathrm{s}} \leftarrow \gamma\right|_{\dot{\gamma}=0}$. 


\subsection{Magneto-sensitivity}

Magnetic sensitivity is introduced in connection with $\gamma_{1 / 2}, \tau_{\text {fmax }}$ and $G_{\mathrm{e}}$ according to the following relations

$$
\begin{gathered}
G_{\mathrm{e}}=\left[1+\left(\frac{M}{M_{\mathrm{s}}}\right)^{2} \delta_{1}\right] G_{\mathrm{e} 0}, \\
\gamma_{1 / 2}=\frac{\gamma_{1 / 20}}{1+\left(\frac{M}{M_{\mathrm{s}}}\right)^{2} \delta_{2}}, \\
\tau_{\text {fmax }}=\left[1+\left(\frac{M}{M_{\mathrm{s}}}\right)^{2} \delta_{3}\right] \tau_{\text {fmax } 0},
\end{gathered}
$$

where $M$ represents magnetization perpendicular to the shear direction, $M_{s}$ saturation magnetization and $\delta_{1}, \delta_{2}$ and $\delta_{3}$, real and positive material constants. The parameters $G_{\mathrm{e} 0}, \gamma_{1 / 20}$ and $\tau_{\text {fmax } 0}$ represent respectively the zero state values.

\subsection{Total behaviour}

The model is developed from these assumptions and parameters are optimized with respect to experimental values for the natural MS rubber for the smallest strain and subsequently validated for the higher ones. A comparison with experimental data is made showing very good agreement. This is displayed for the lowest amplitude in Figs. 6 and 7 and for a higher one in Figs. 8 and 9. The following parameter values are used: $G_{\mathrm{e} 0}=1.35 \mathrm{MN} \mathrm{m}^{-2}, b=0.12 \mathrm{M} \mathrm{N} \mathrm{m}^{-2} \mathrm{~s}^{\alpha}, \alpha=0.36, \gamma_{1 / 20}=0.00103$, $\tau_{\text {fmax } 0}=0.9 \mathrm{k} \mathrm{N} \mathrm{m}^{-2}, \delta_{1}=2.22, \delta_{2}=6.94, \delta_{3}=1.53$ and $\mu_{0} M_{s}=0.6 \mathrm{~T}$, where $\mu_{0}$ is the permeability of free space. 


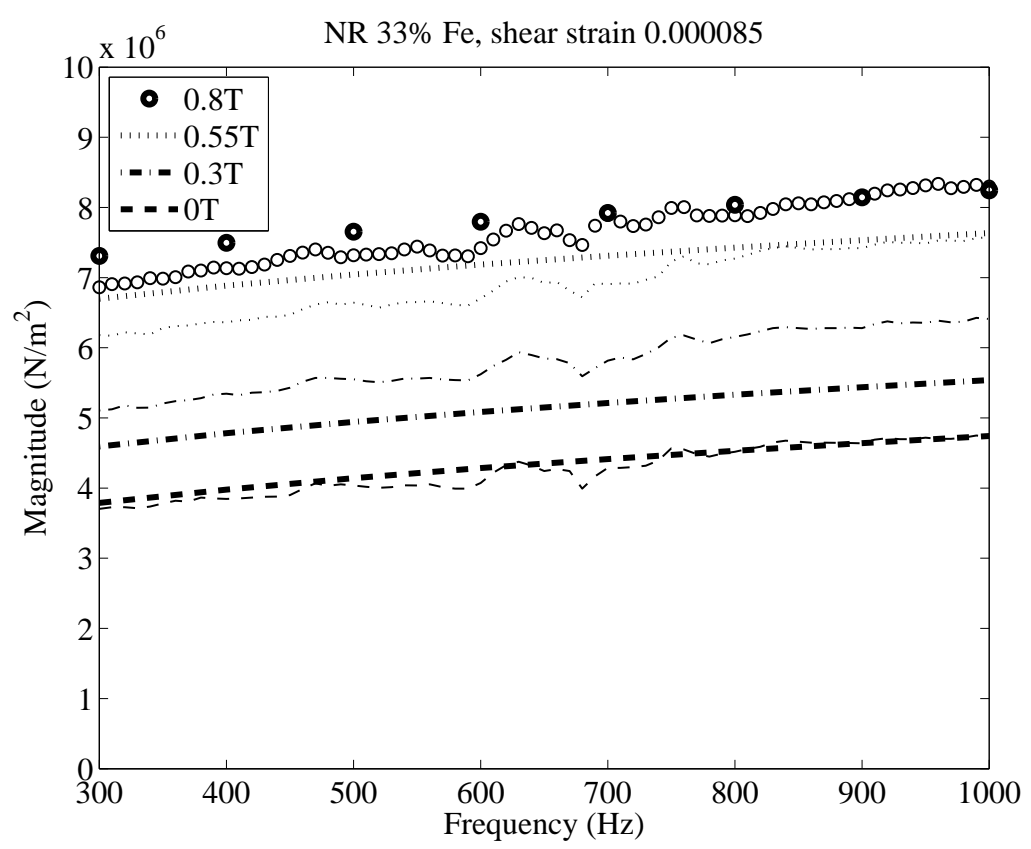

Figure 6: Experimentally obtained shear modulus magnitude $|G|$ (thin lines) and corresponding modeled results (thick lines) versus frequency at induced magnetic field of $0,0.3,0.55$ and $0.8 \mathrm{~T}$.

\section{Applications - MS rubber isolators}

One commonly used means to reduce energy transmission travelling in the shape of vibrations is to decouple the source from the receiver by inserting a flexible element. Rubber possesses the proper characteristics and such isolators are consequently used in various industrial applications. The fundamental idea behind a vibration isolator within the audible frequency range is to provide a mechanical property mismatch between the source and the receiving structure; the mismatch acting as a mirror in reflecting the audio vibrations from the source backwards. As the source and receiving structure are usually stiff, a suitable isolator is accordingly soft; the softer the isolator the larger the attenuation, with zero stiffness as an optimum, that is, replacing the isolators by empty 


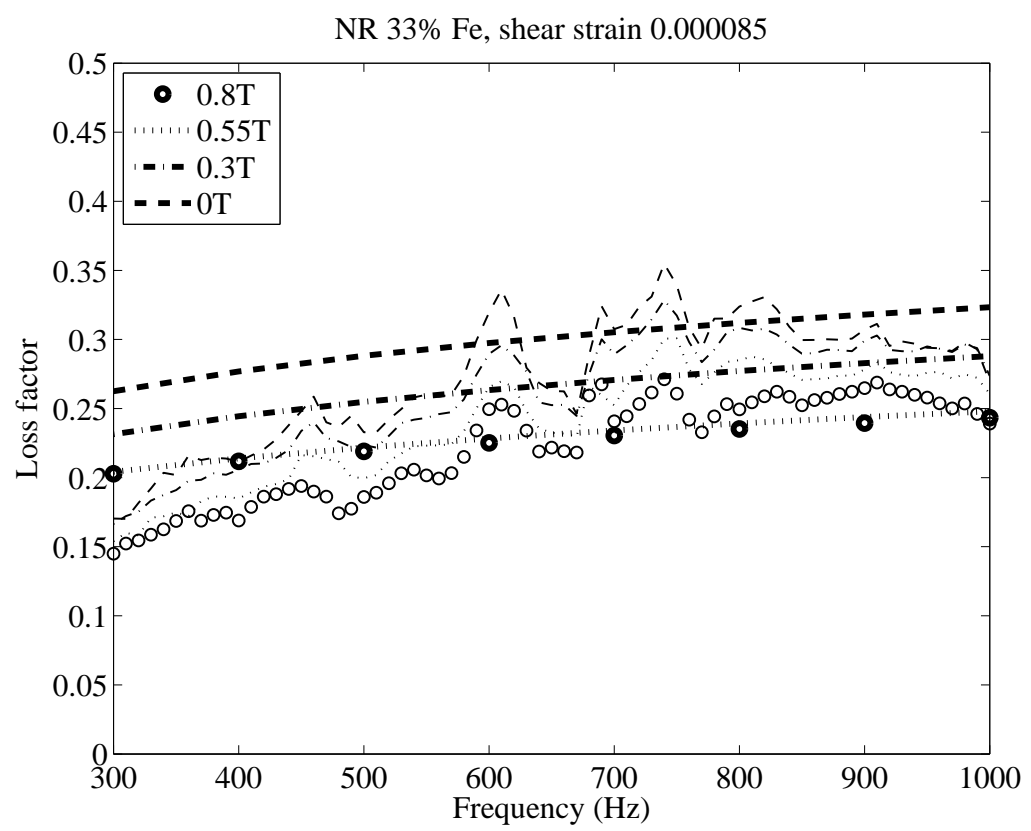

Figure 7: Experimentally obtained shear modulus loss factor Imag $G / \operatorname{Real} G$ (thin lines) and corresponding modeled results (thick lines) versus frequency at induced magnetic field of $0,0.3,0.55$ and $0.8 \mathrm{~T}$.

space. If structure-borne sound attenuation were the only goal, such a solution would suffice. However, as isolators also carry the source, provide dynamic and static stability etc., the attenuation optimization process has to be solved with strongly restricted design parameters-clearly, excluding the zero stiffness solution. Typically, a vehicle for instance, is subjected to vibrations of largely varying frequencies whereas isolators are normally optimized with respect only to low frequency requirements. Hence, the high frequency properties are liable to be poor over large regions. The ability to reversibly, rapidly and effectively control the properties of a component would provide an effective means to meet high frequency requirements too, thus reducing noise and vibrations which is a sought-after quality in industrial applications. In the previous section it was shown that MS rubber possesses the characteristics suitable to 


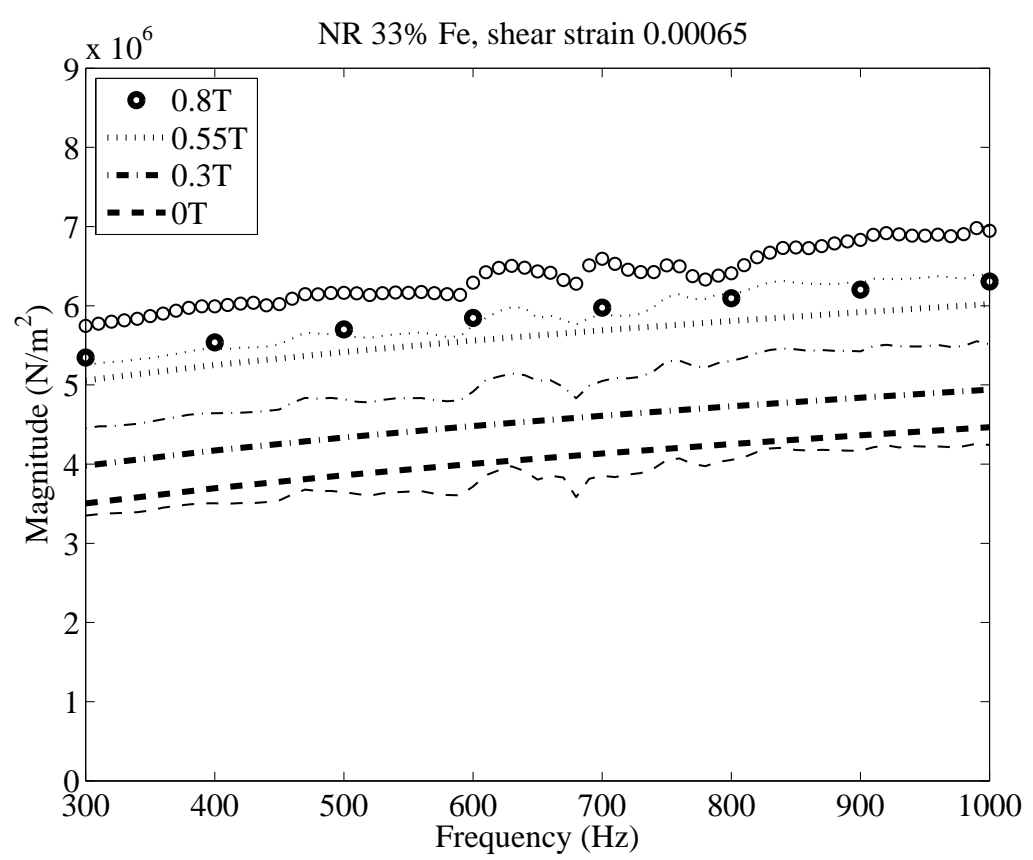

Figure 8: Experimentally obtained shear modulus magnitude $|G|$ (thin lines) and corresponding modeled results (thick lines) versus frequency at induced magnetic field of $0,0.3,0.55$ and $0.8 \mathrm{~T}$.

the purpose; while strongly magneto-sensitive - reacting strongly, rapidly and reversibly to an externally applied field - it nevertheless retains the classical rubber properties for which rubber was originally chosen. Since the field of research is relatively new, very few applications exist. There is, however, as shown in this section, an enormous potential for MS rubber in an application's context.

\subsection{Torsionally excited cylindrical isolator}

The application considered presented in Paper B is a magnetic field exposed, cylindrical vibration isolator of height $H=100 \mathrm{~mm}$ and diameter $D=150 \mathrm{~m}$, portrayed in Fig. 10. It is bonded to two circular steel plates and torsionally excited by a rotation of $\Omega_{\mathrm{e}}$ radians at the upper lateral 


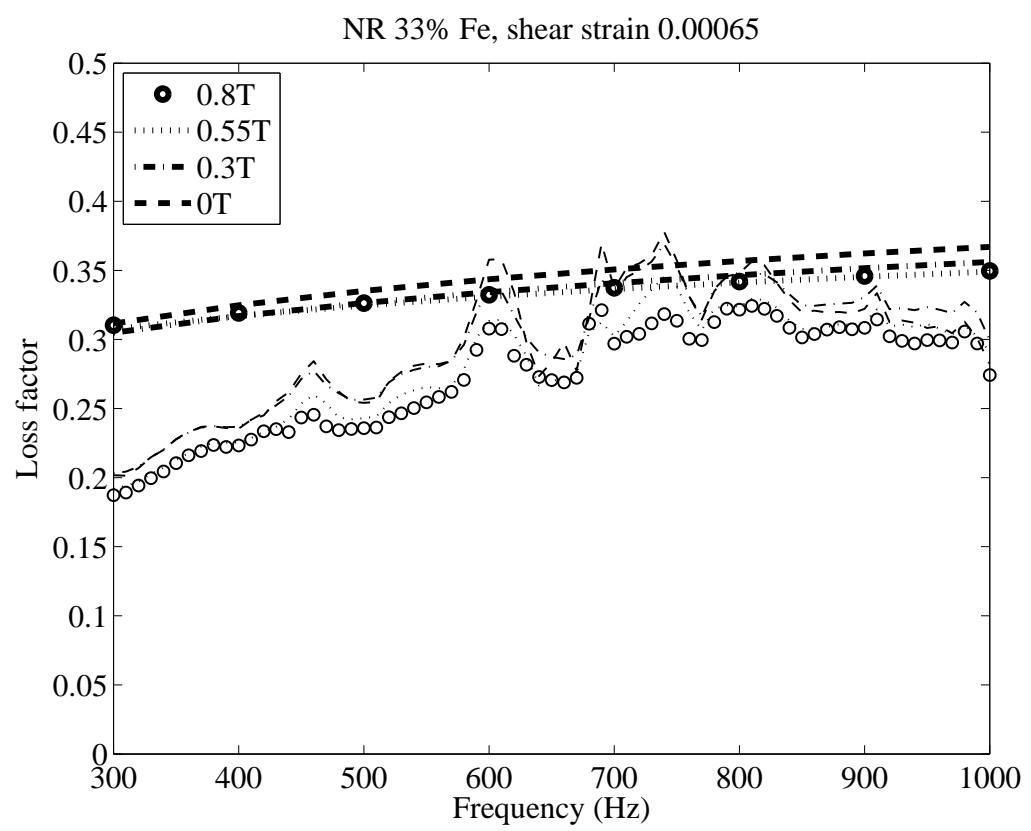

Figure 9: Experimentally obtained shear modulus loss factor $\operatorname{Imag} G / \operatorname{Real} G$ (thin lines) and corresponding modeled results (thick lines) versus frequency at induced magnetic field of $0,0.3,0.55$ and $0.8 \mathrm{~T}$.

surface, while blocked at the lower surface by an applied torsional moment of $T \mathrm{Nm}$. The magneto-sensitive rubber consists of natural rubber containing $33 \%$ iron. A strain sufficiently small to permit a linearization with respect to amplitude is opted in order to permit the use of data from Fig. 3. The wave equation for torsional motion in the frequency domain reads ref.(32)

$$
\frac{\partial^{2} \Omega(z, \omega)}{\partial z^{2}}+k_{\mathrm{T}}^{2} \Omega(z, \omega)=0 .
$$

Defining the wave number $k_{\mathrm{T}}$ (see Eq.(12)), boundary conditions and calculating the shear stress $\sigma(\omega)$ at the lower surface leads to the following transfer stiffness relation

$$
k=\frac{T}{\Omega_{\mathrm{e}}}=\int_{0}^{D / 2} \frac{\sigma 2 \pi r^{2}}{\Omega_{\mathrm{e}}} \mathrm{d} r=\frac{\pi G k_{\mathrm{T}} D^{4}}{32 \sin \left(k_{\mathrm{T}} H\right)} .
$$




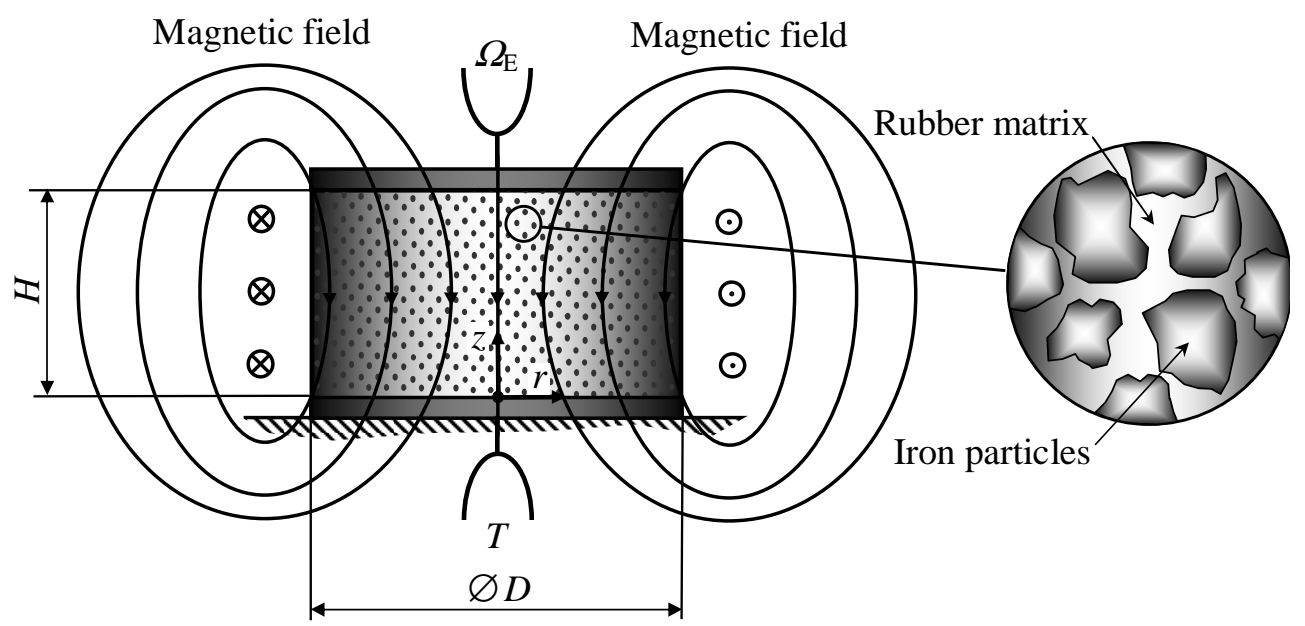

Figure 10: Magnetic field applied on a torsionally excited cylindrical vibration isolator of natural rubber with an iron particle volume concentration of $33 \%$.

The transfer stiffness is displayed in Fig. 11 for four magnetic inductions of $0,0.3,0.55$ and $0.8 \mathrm{~T}$ in the frequency range of 100 to $1000 \mathrm{~Hz}$. Approximately, optimal isolation within this frequency range is obtained with as low a magnitude of the transfer stiffness as possible. The path traced with circles indicates the optimal isolation for different frequencies. The magnitude graphs show an almost $15 \mathrm{~dB}$ drop at around $150 \mathrm{~Hz}$ obtained by applying a magnetic field of $0.8 \mathrm{~T}$. Once the $0 \mathrm{~T}$ dynamic stiffness peak has been passed the magnetic field can be switched off according to the optimal path graph. This, of course, is a reversible process, meaning that frequencies can be shifted up and down and back and forth. Furthermore it can be done rapidly, due to iron's magnetic properties.

\subsection{Axially excited MS rubber bushing}

This application presented in Paper $\mathbf{C}$ concerns an isolator standing on a concrete floor of infinite extent, viewed in Fig. 12. It consists of a magneto-sensitive rubber bushing firmly bonded to an exterior circu- 

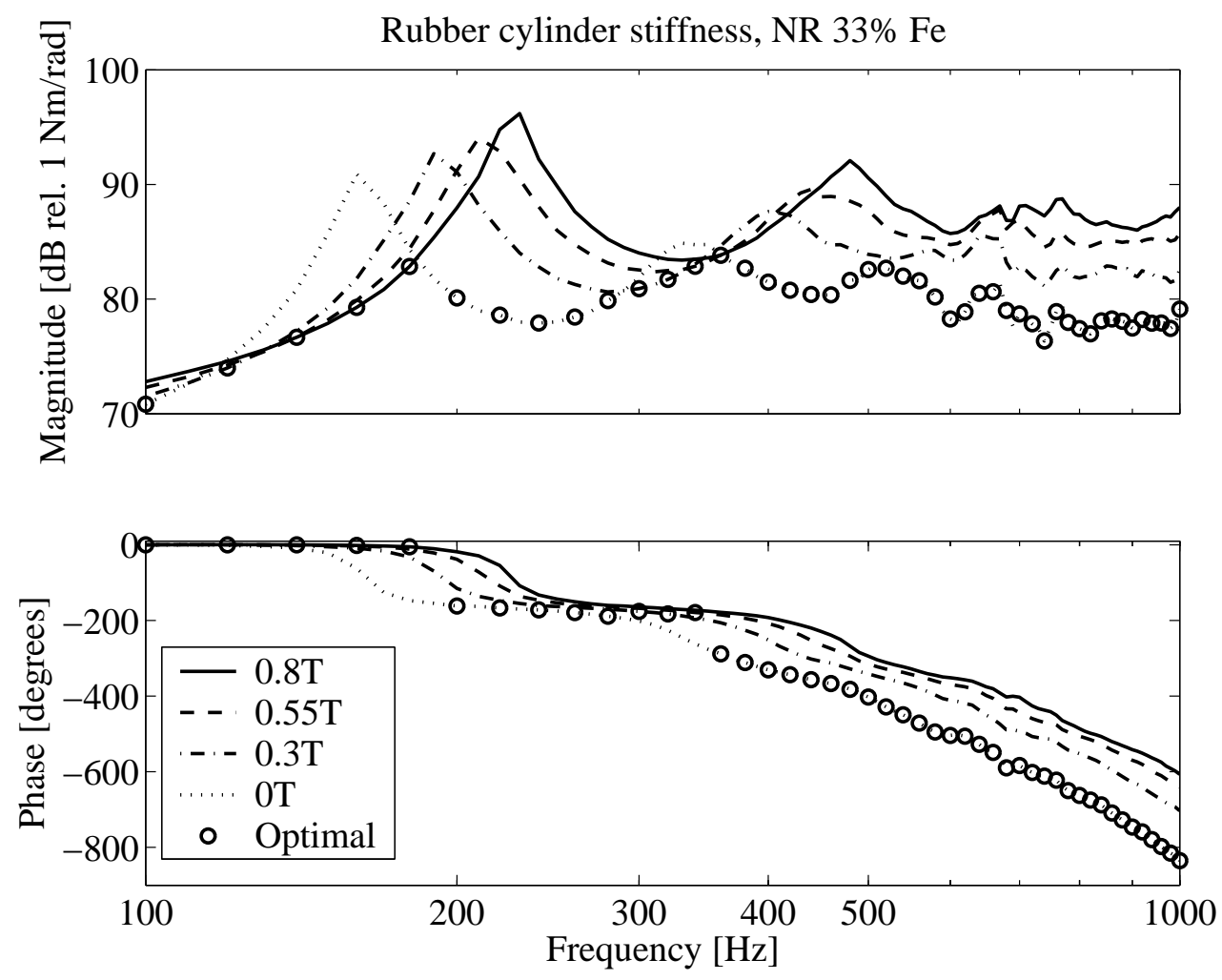

Figure 11: Torsional stiffness magnitude and loss factor versus frequency for a cylindrical vibration isolator of natural rubber with an iron particle volume concentration of $33 \%$.

lar iron shell and to an interior iron rod connecting to the floor. The cylindrical shell supports a force excited rigid mass acting as a simplified source model. The geometrical dimensions are: inner radius $R_{\mathrm{i}}=0.01 \mathrm{~m}$, outer radius $R_{\mathrm{o}}=0.08 \mathrm{~m}$, the length of the rubber bushing $L=0.25 \mathrm{~m}$ and the thickness of the floor $h_{\mathrm{f}}=0.10 \mathrm{~m}$. The applied mass $m_{1}$ amounts to $1000 \mathrm{~kg}$. The iron rod mass $m_{2}$ is calculated to $1 \mathrm{~kg}$ for a typical steel density $\rho_{\text {steel }}=7800 \mathrm{~kg} \mathrm{~m}^{-3}$. The density of the rubber is set to $\rho=3250 \mathrm{~kg} \mathrm{~m}^{-3}$ and the concrete floor $\rho_{\mathrm{f}}=2300 \mathrm{~kg} \mathrm{~m}^{-3}$. The latter has a complex elasticity modulus $E_{\mathrm{f}}=2.6 \times 10^{10}(1+0.02 \mathrm{i}) \mathrm{N} \mathrm{m}^{-2}$ where $\mathrm{i}$ is the imaginary unit. The Poisson's ratio for the same is $\nu_{\mathrm{f}}=0.2$. The magneto-sensitive rubber 
consists of natural rubber with an iron particle volume concentration of $33 \%$. The particles are randomly dispersed within the rubber and irregularly shaped. A strain sufficiently small to permit a linearization with respect to amplitude is opted in order to permit the use of data from Fig. 3.

The axially symmetric transversal wave equation for axial shear waves propagating radially in the frequency domain reads in cylindrical coordinates

$$
\frac{\partial^{2} \widetilde{u}(r, \omega)}{\partial r^{2}}+\frac{1}{r} \frac{\partial \widetilde{u}(r, \omega)}{\partial r}+k_{\mathrm{T}}^{2} \widetilde{u}(r, \omega)=0
$$

where the transversal wave number (33)

$$
k_{\mathrm{T}}=\omega \sqrt{\frac{\rho}{G}},
$$

the angular frequency $\omega=2 \pi f, G$ is the shear modulus, $f$ the frequency and the frequency domain variables are obtained by the temporal Fourier transform defined as $(\widetilde{*})=\int_{-\infty}^{\infty}(\cdot) \exp (-\mathrm{i} \omega t) \mathrm{d} t$. Also modelling the floor stiffness relating the motion of the foundation to the force acting on it as ref.(32),

$$
k_{\mathrm{f}}=\mathrm{i} \omega 8 h_{\mathrm{f}}^{2} \sqrt{\frac{E_{\mathrm{f}} \rho_{\mathrm{f}}}{12\left[1-\nu_{\mathrm{f}}^{2}\right]}},
$$

the transmissibility - defined as the ratio of the energy flow into the floor with and without isolator - for the two cases of an applied and no applied magnetic field can be calculated, and is displayed in Fig. 13. Optimal isolation corresponds to as low an energy flow transmissibility as possible; around $200 \mathrm{~Hz}$ a large reduction in transmitted energy is obtained when magnetically saturating the rubber. It is the first internal antiresonance - the first dynamic peak stiffness frequency - that is shiftable upwards in frequency by applying a magnetic field. In this manner a maximum reduction of approximately $7 \mathrm{~dB}$ is obtained. Naturally the shifting of critical frequencies can be done reversibly by turning off the magnetic field. Also at the second peak, optimum tends to occur for the saturated state curve. 


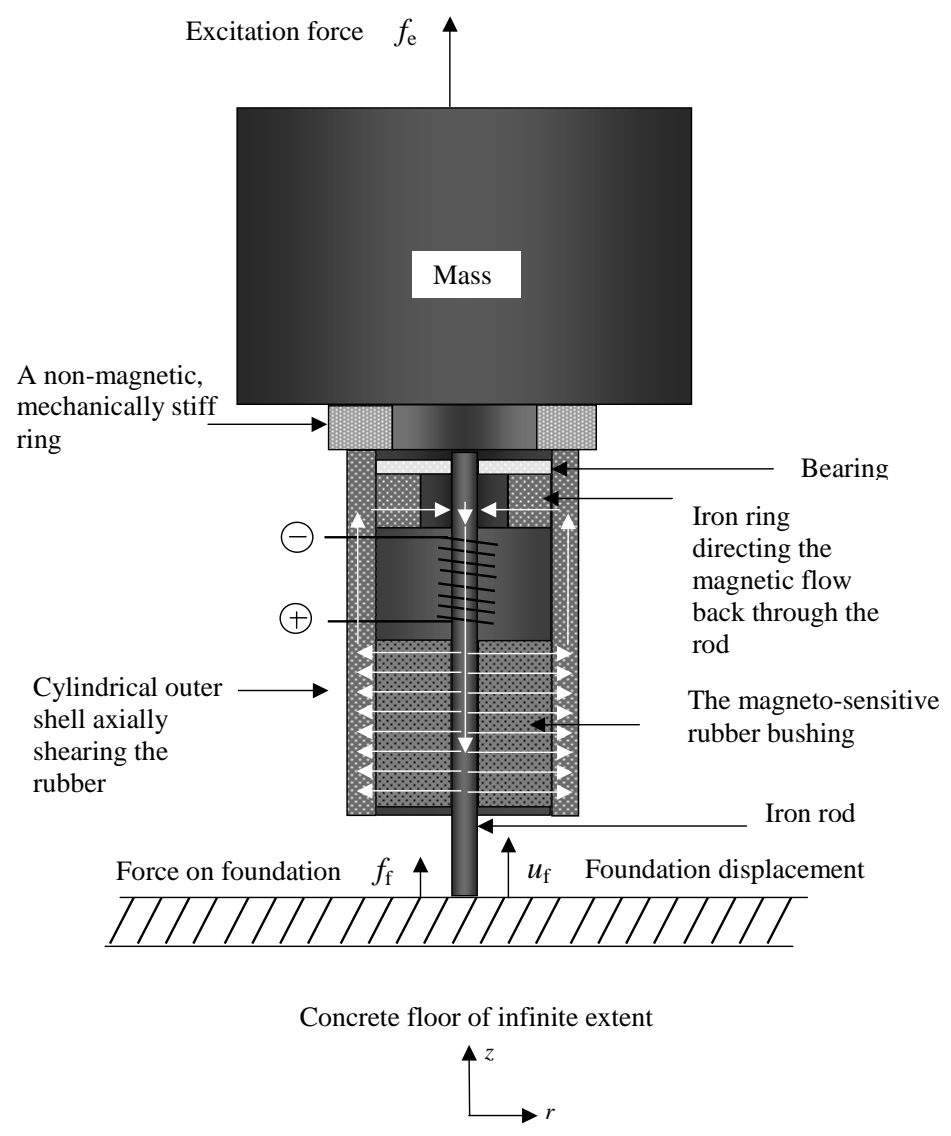

Figure 12: Picture of the axially symmetric designed model.

\subsection{Torsionally excited MS rubber bushing}

While some general bushing models include amplitude dependence refs.(34)(36) none of them includes magneto-sensitivity. By employing the presented constitutive equation from Paper D in an effective engineering formula for the torsional stiffness of a rubber bushing, a frequency, amplitude and magnetic field dependent torsional stiffness model of a magnetosensitive natural rubber bushing is built. This work is presented in Paper E.

The bushing with inner radius $a$, outer radius $b$ and length $L$, is 


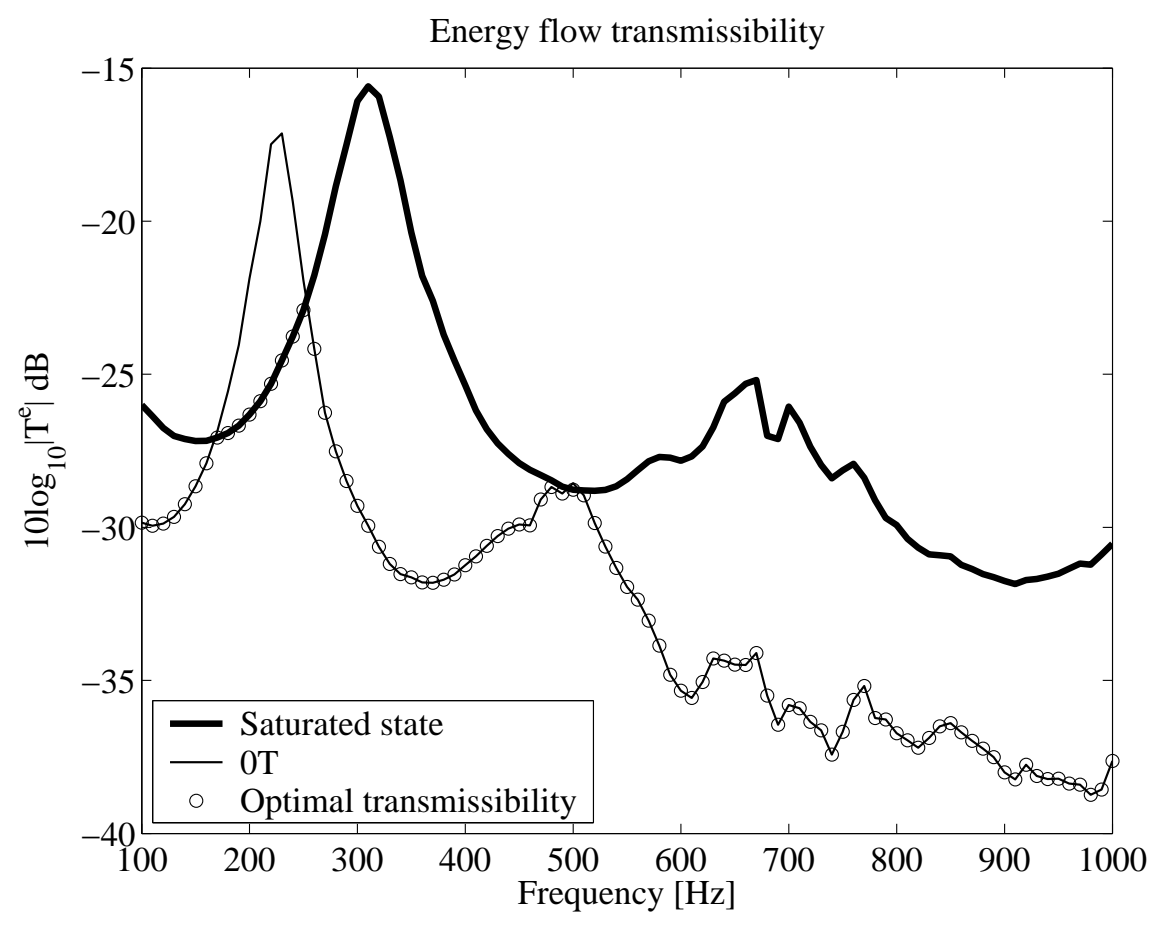

Figure 13: Energy flow transmissibility with and without magnetic field. The path for optimal isolation is marked by circles.

subjected to a torsion angle $\varphi(t)$. A picture of the magneto-sensitive rubber bushing can be viewed in Fig. 14 . 


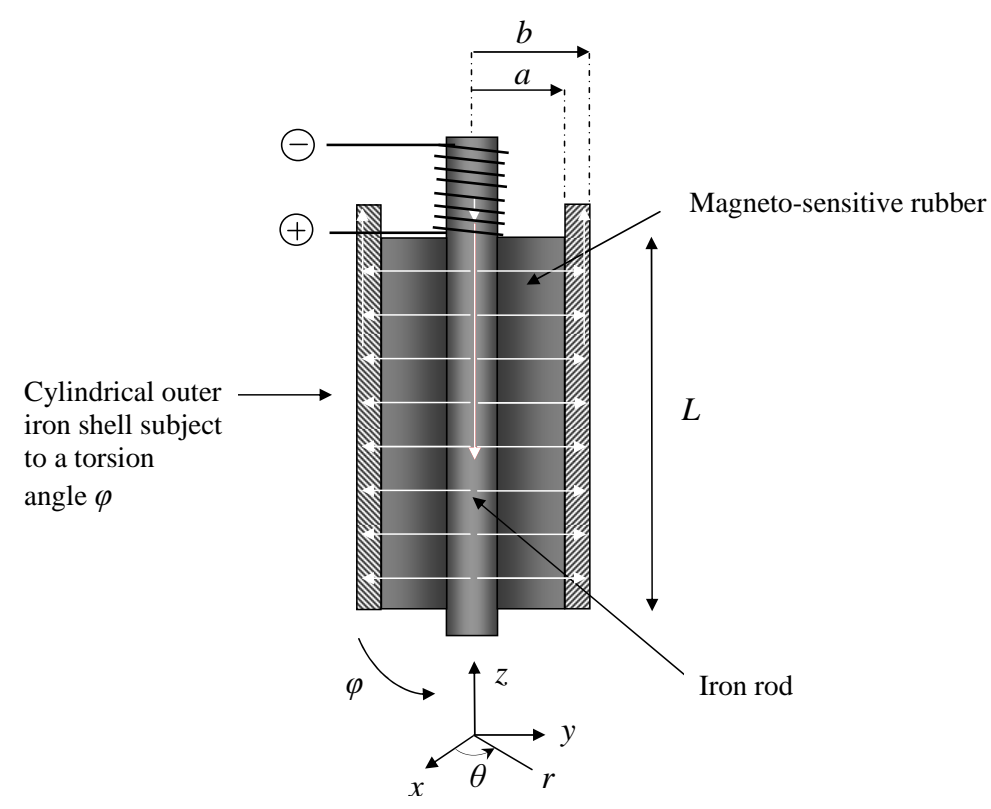

Figure 14: Picture of the axially symmetric designed magneto-sensitive rubber bushing.

First an average engineering shear strain is calculated through a volume average (37).

$$
\bar{\gamma}_{r \theta}(t)=\frac{4 b^{2} a^{2} \varphi(t)}{\left(b^{2}-a^{2}\right)^{2}} \log _{e}\left(\frac{b}{a}\right),
$$

where $t$ signifies time and the subscripts $r$ and $\theta$ denote cylindrical coordinate directions. Next, this equivalent strain is inserted into the constitutive equation yielding a stress response. Taking the fourier transform of both stress and strain and linearizing, that is dropping overtones in the stress response, an expression for the strain averaged frequency and amplitude dependent shear modulus is obtained,

$$
\bar{G}=\frac{\widetilde{\tau}(\omega)}{\widetilde{\gamma}(\omega)}
$$


From this relation the torsional dynamic stiffness of the magneto-sensitive rubber isolator can be calculated as

$$
k_{\mathrm{dyn}}=\frac{4 \pi L a^{2} b^{2} \bar{G}(\omega)}{b^{2}-a^{2}} .
$$

The constitutive equation parameters have the same values as the ones presented in the modelling section. Isolator dimensions are: $L=0.025 \mathrm{~m}$, $a=0.02 \mathrm{~m}$ and $b=0.025 \mathrm{~m}$. The dynamic torsional stiffness is modelled for four different torsional angles; the results for the smallest one is plotted in Fig. 15 and Fig. 16, and for a higher one in Fig. 17 and Fig. 18. The results predict, and clearly display, the possibility of controlling over a large frequency range through the application of a magnetic field, the magneto-sensitive rubber bushing stiffness for different amplitudes. 


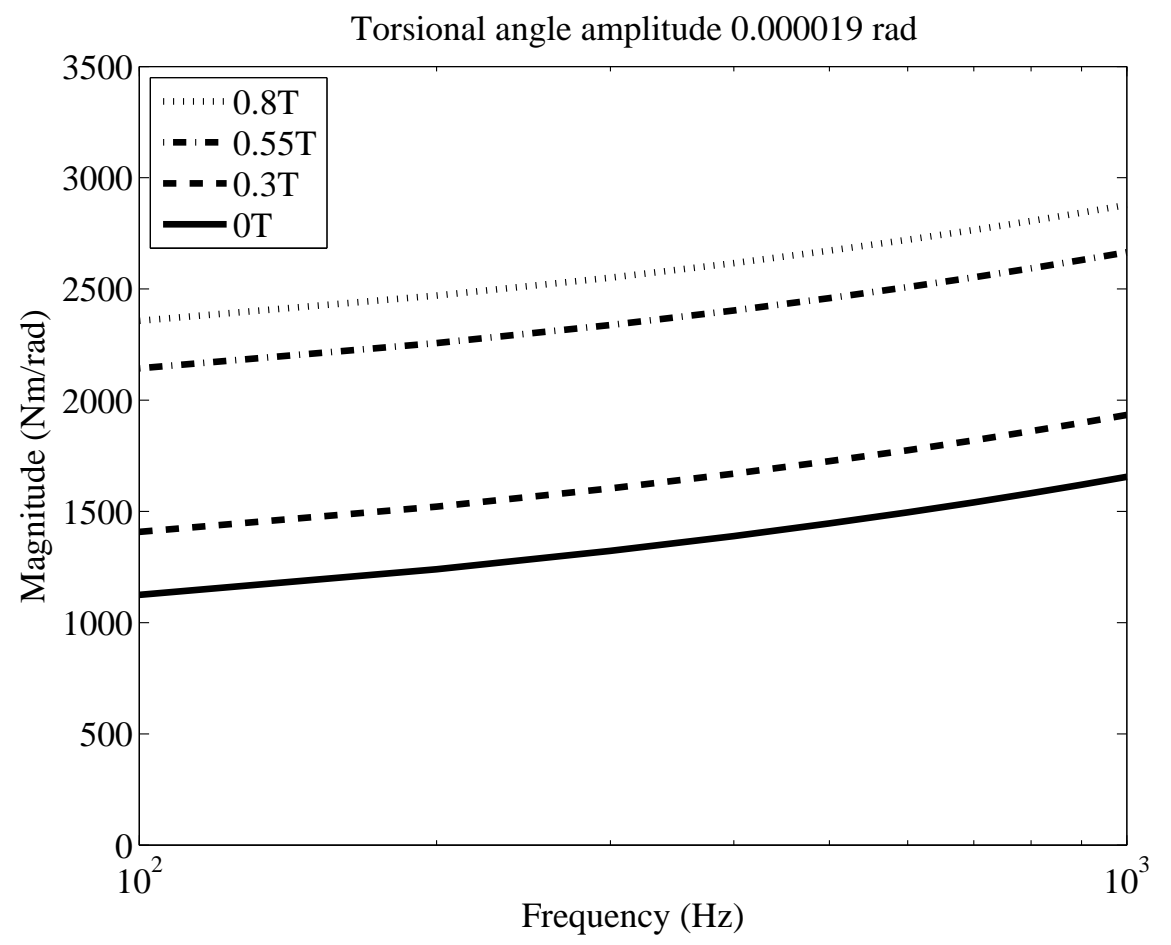

Figure 15: Torsion stiffness magnitude versus frequency at induced magnetic field of $0,0.3,0.55$ and $0.8 \mathrm{~T}$. 


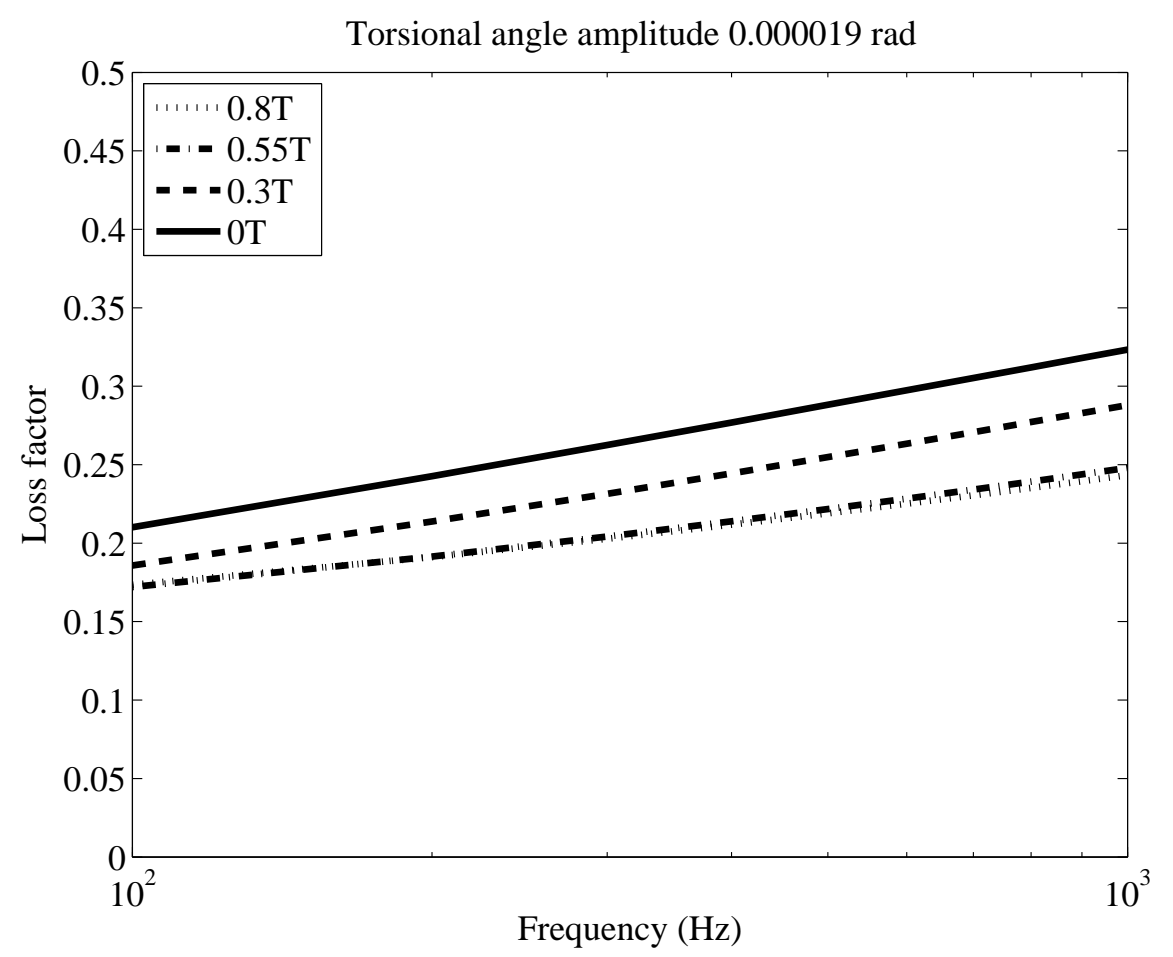

Figure 16: Torsion stiffness loss factor versus frequency at induced magnetic field of $0,0.3,0.55$ and $0.8 \mathrm{~T}$. 


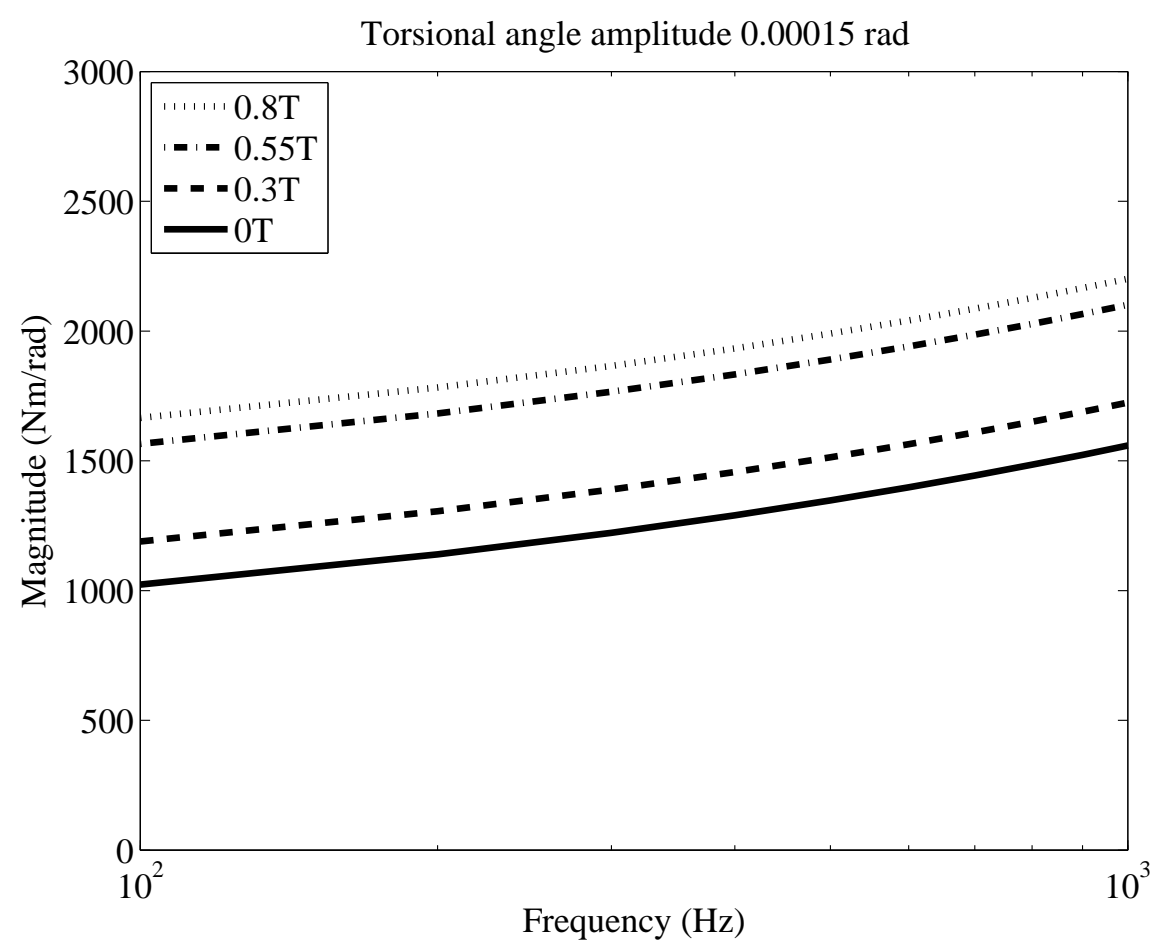

Figure 17: Torsion stiffness magnitude versus frequency at induced magnetic field of $0,0.3,0.55$ and $0.8 \mathrm{~T}$. 


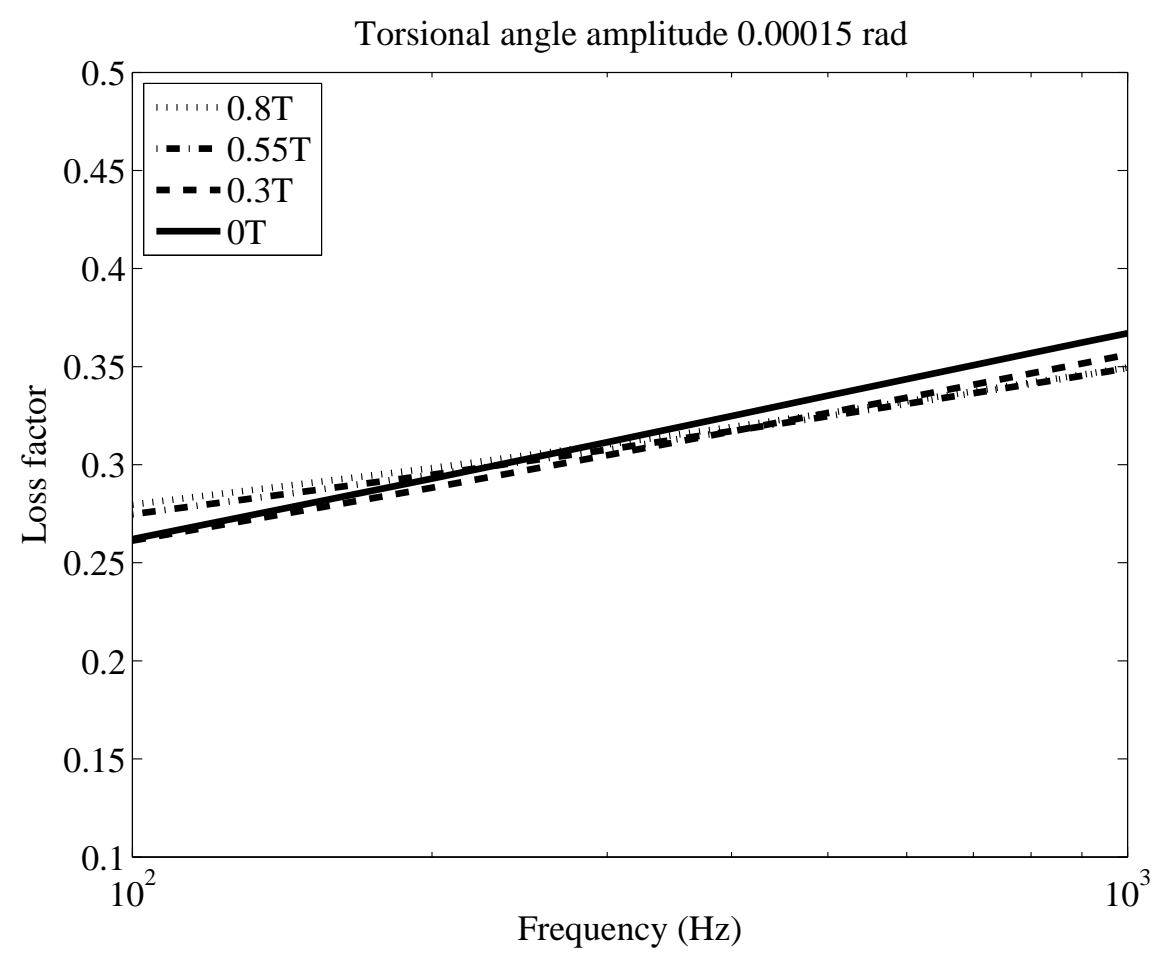

Figure 18: Torsion stiffness loss factor versus frequency at induced magnetic field of $0,0.3,0.55$ and $0.8 \mathrm{~T}$. 


\section{Future Research}

The presented work is believed to put forth the potential of magnetosensitive rubber as an effective means to readily improve existing rubber isolators in the audible frequency range. Aside from experimentally proving its potential, various aspects are considered and models presented. Nevertheless, it would be interesting to expand this work in several directions:

-On the experimental side investigate how an applied prestrain on the magneto-sensitive rubber reflects on the magnetic sensitivity, and possibly model its effects.

-Model and investigate the possibilities of improving existing absorbers through the use of magneto-sensitive rubber.

-From the work presented in Paper D create an enhanced constitutive model permitting geometrical non-linearities and finite deformations.

-Model the applications in Paper $\mathbf{B}$ and $\mathbf{C}$ with the constitutive model presented in Paper $\mathbf{D}$ to investigate the influences of the amplitude dependence. 


\section{References}

[1] Rabinow J. The Magnetic Fluid Clutch. AIEE Trans 1948;67:130815.

[2] Winslow WM. Induced Fibration of Suspensions. Journal of Applied Physics 1949;20:1137-40.

[3] Carlson JD, Jolly MR. MR fluid, foam and elastomer devices. Mechatronics 2000;10:555-69.

[4] Demchuk SA, Kuz'min VA . Viscoelastic properties of magnetorheological elastomers in the regime of dynamic deformation. Journal of Intelligent Material Systems and Structures 2002;75(2):396-0.

[5] Kari L, Lokander M, Stenberg B. Structure-borne sound properties of isotropic magneto-rheological elastomers. Kautschuk Gummi Kunststoffe;2002;12:669-73.

[6] Lokander M, Stenberg B. Improving the magnetorheological effect in isotropic magnetorheological rubber materials. Polymer Testing 2003;22(6):677-80.

[7] Lokander M, Stenberg B. Performance of isotropic magnetorheoogical rubber materials. Polymer Testing 2003;22(3):245-51.

[8] Occhiuzzi A, Spizzuoco M, Serino G. Experimental analysis of magnetorheological dampers for structural control. Smart Materials and Structures 2003;12:703-11.

[9] Yalcintas M, Dai H. Vibration suppression capabilities of magnetorheological materials based adaptive structures. Smart Materials and Structures 2004;13:1-11.

[10] $\mathrm{Hu}$ Y, Wang YL, Gong XL, Gong XQ, Zhang XZ, Jiang WQ, Zhang PQ, Chen ZY. New magnetorheological elastomers based on polyurethane/Si-rubber hybrid. Polymer Testing 2005;24(3):324-29. 
[11] Zhou GY, Wang Q. Study on the adjustable rigidity of magnetorheological-elastomer-based sandwich beams. Smart Materials and Structures 2006;15:59-74.

[12] Goncalves FD, Ahmadian M, Carlson JD. Investigating the magnetorheological effect at high flow velocities. Smart Materials and Structures 2006;15:75-85.

[13] Carmignani, Forte P, Rustighi E. Design of a novel magnetorheological squeeze-film damper. Smart Materials and Structures 2006;15:164-70.

[14] Fletcher WP, Gent AN. Non-Linearity in the Dynamic Properties of Vulcanised Rubber Compounds. Transactions, I.R.I. 1953;29:266-80.

[15] Coveney VA, Johnsson DE, Turner DM. A triboelastic model for the cyclic behavior of filled vulcanizates. Rubber Chemistry of Technology 1995;68:660-70.

[16] Austrell PE, Olsson AK, Jonsson M. A method to analyse the nonlinear dynamic behavior of rubber components using standard FE codes. Conference on Solid Mechanics 2001;464.

[17] Bruni S, Collina A. Modelling of viscoelastic behavior of elastomeric components: an application to the simulation of train-track interaction. Vehicle System Dynamics 2000;34:283-301.

[18] Berg M. A non linear rubber spring model for rail vehicle dynamic analysis. Vehicle System Dynamics 1998;30:197-212.

[19] Sjöberg M, Kari L. Non-linear behavior of a rubber isolator system using fractional derivatives. Vehicle System Dynamics 2002;37:21736.

[20] Davis LC. Model of magnetorheological elastomers. Journal of Applied Physics 1999;85,3348-51. 
[21] Brigadnov IA, Dorfmann A. Mathematical modeling of magnetosensitive elastomers. International Journal of Solids and Structures 2003;40:4659-74.

[22] Dorfmann A and Ogden RW. Magnetoelastic modelling of elastomers. European Journal of Mechanics A-Solids 2003;22:497-07.

[23] Dorfmann A and Ogden RW. Nonlinear magnetoelastic deformations. Quarterly Journal of Mechanics and Applied Mathematics 2004;57(4); 599-622.

[24] Kankanala SV, Tryantafyllidis N. On finitely strained magnetorheological elastomers. Journal of the Mechanics and Physics of Solids 2004;52:2869-2908.

[25] Shen Y, Golnaraghi MF, Heppler GR. Experimental research and modeling of magnetorheological elastomers. Journal of Intelligent Material Systems and Structures 2004;15(1):27-35.

[26] Ginder JM, Clark SM, Schlotter WF, Nichols ME. Magnetostrictive phenomena in magnetorheological elastomers. International Journal of modern physics B 2002;16(17-18):2412-18.

[27] Bellan C, Bossis G. Field dependence of viscoelastic properties of MR elastomers. International Journal of modern physics $\mathrm{B}$ $2002 ; 16(17-18): 2447-53$.

[28] Bossis G, Coquelle E, Kuzhir P. Adaptive magnetorheological materials. Annales de Chimie Science de Matriaux 2004;29(6):43-54.

[29] Blom P, Kari L. Amplitude and frequency dependence of magnetosensitive rubber in a wide frequency range. Polymer Testing $2005 ; 24: 656-62$.

[30] Bagley RL, Torvik PJ. Fractional calculus-A different appoach to the analysis of viscoelastically damped structures. American Institute of Aeronautics and Astronautics Journal 1983;21:741-48. 
[31] Sjöberg M, Kari L. Nonlinear isolator dynamics at finite deformations: an effective hyperelastic, fractional derivative, generalized friction model. Nonlinear Dynamics 2003;33(3):323-336.

[32] Cremer L, Heckl M. Structure-Borne Sound 1988.

[33] Graff. Wave motion in elastic solids 1975.

[34] Morman KN, Pan TY. Application of finite element analysis in the design of automotive elastomeric componentes. Rubber Chemistry and Technology 1988;61(3):503-33.

[35] Adkins JE, Gent AN. Load-deflexion relations of rubber bush mountings. British Journal of Applied Physics 1954;5:354-8.

[36] Kari L. Dynamic stiffness matrix of a long rubber bush mounting. Rubber Chemistry and Technology 2002;75(4):747-70.

[37] García Tárrago JM, Kari L. An effective engingeering formula for torsion stiffness of a rubber bush including amplitude dependence. Constitutive models for rubber IV 2005; Proceedings:319-23. 